\title{
INFLUENCIA DEL PROCESO DE ENSEÑANZA ESCOLAR FISCAL EN LA SOCIALIZACIÓN DE MUJERES Y HOMBRES AYMARA DE LA ZONA ALTIPLÁNICA DEL NORTE DE CHILE
}

\author{
Ana María Carrasco Gutiérrez y Vivian Gavilán Vega ${ }^{2}$
}

\section{$*$ Introducción}

Resumen

El artículo expone resultados de investigación sobre los procesos de escolarización de la población aymara del norte de Chile desde una perspectiva de género y aborda la influencia del sistema escolar formal en la socialización aymara altiplánica, desde la llegada de la escuela nacional a la zona, fundamentalmente durante la segunda mitad del siglo XX. Se entrega información sobre los programas escolares de enseñanza primaria, con el objeto de conocer y reflexionar acerca del papel jugado por el sistema escolar en los cambios de la división del trabajo por género en esta población, a partir de entrevistas a mujeres y hombres sobre su experiencia escolar, como alumnos/as y apoderados/as; a profesores/as, como agentes educativos; $y$ a través del análisis de contenido de los textos escolares más utilizados.

Palabras claves: educación primaria estatal - socialización - división del trabajo por género.

\begin{abstract}
This article presents the results on the investigation of the schooling processes of the Aymara population of northern Chile from a gender perspective and addresses the influence of formal schooling system in the socialization of the Aymara people of the altiplano since the arrival of the national school system in the area during the second half of the $20^{\text {th }}$ century. We discuss the information about the elementary school curriculum in order to know and consider the role played by the school system in the changes of gender labour division among this population, based on interviews with women and men about their school experience as students and parents, with teachers, as educational agents, and through the content analysis of the most widely used textbooks.
\end{abstract}

Key words: state elementary education - socialization - gender division of labour.

Recibido: mayo 2010. Aceptado: diciembre 2012.

\footnotetext{
${ }^{1}$ Departamento de Antropología, Facultad de Ciencias Sociales y Jurídicas (FACSOJUR), Universidad de Tarapacá. Arica, CHILE. Email: amcarrasco@uta.cl

2 Departamento de Antropología, Facultad de Ciencias Sociales y Jurídicas (FACSOJUR), Universidad de Tarapacá. Arica, CHILE. Email: vtgavilanv@uta.cl
}

El propósito del presente artículo es abordar la influencia del proceso escolar formal estatal en el aprendizaje e interiorización de normas y valores por parte de la población aymara en el altiplano chileno, abarcando desde fines de la primera y toda la segunda mitad del siglo XX. Específicamente, se presentan resultados de investigación etnográfica que permiten conocer, analizar y reflexionar acerca del rol que ha cumplido el sistema educacional chileno en los procesos de socialización de género en este grupo étnico.

La Escuela Nacional, como se llamó durante la primera mitad del siglo XX, se instala en las distintas localidades rurales - de lo que hoy corresponden a las regiones $\mathrm{XV}$ de Arica-Parinacota y I de Tarapacá- a partir de la década de 1930, momento en el que comienza a compartir la enseñanza con la familia y la comunidad. En ese contexto surgen las preguntas: ¿Cuáles son los contenidos valóricos y cuáles los modelos de género que la Escuela Nacional ha transmitido a la población aymara? ¿Cómo éstos han influido en los cambios que han experimentado los roles de género entre los aymara? Nuestro supuesto principal es que el sistema educacional, por ser una de las principales instituciones del Estado que transmiten las ideologías del poder, no será en ningún caso indiferente al comportamiento adquirido por mujeres y hombres aymara.

Para dar respuesta a estas interrogantes, determinamos como período de estudio el comprendido entre 1950 y 1990 , a causa de la mayor cantidad de antecedentes 
etnográficos e históricos que manejamos respecto de la presencia de la escuela en el sector aymara altiplánico del norte de Chile, y porque corresponde a un momento que refleja la llegada y pleno funcionamiento de la escuela nacional en la zona.

Metodológicamente, seguimos tres procedimientos. Primero, debido a que la escuela es por excelencia una instancia de transmisión de valores, nos pareció pertinente analizar los contenidos de los textos escolares más utilizados, seleccionándose siete de ellos. ${ }^{3}$ El análisis de los textos pone énfasis en los contenidos transmitidos, dejando abierta la posibilidad de un estudio en profundidad de los efectos producidos en los receptores. Segundo, entrevistamos a profesores/as que habían ejercido y ejercían docencia en las comunidades rurales en estudio, en su calidad de importantes agentes de socialización, cuyo rol ha sido el de educar nuevas generaciones, transmitirles conocimientos y afianzar valores y actitudes necesarias para el pleno desarrollo de sus potencialidades. Tercero, consultamos a hombres y mujeres aymara en su condición de alumnos/as y apoderados/as, obteniendo valiosos antecedentes respecto de la experiencia escolar como adultos/padres y como jóvenes/estudiantes.

Con todo, lo que motiva este artículo no es más que compartir, como una primera aproximación a la problemática, la información acopiada y analizada de manera de dimensionar y reflexionar sobre los cambios que provoca, en la vida de hombres y mujeres aymaras, el sistema educacional impuesto por la "escuela formal chilena", ${ }^{4} \mathrm{y}$

3 Silabario Matte. Primera Edición 1902; Silabario Hispanoamericano. Primera Edición 1945; Silabario para adultos "Mi Tierra". Primera Edición 1946; Lea en Colores. Primera Edición 1946; Marka Masi (Somos del mismo pueblo). Primera Edición 1985; El Nuevo Lector Americano, Primera Edición 1928; El Lector Chileno. Primera Edición 1928.

4 Precisamos que estos antecedentes forman parte de un estudio mayor realizado en la zona altiplánica de las actuales regiones XV y I. La metodología utilizada fue de carácter eminentemente cualitativo, utilizándose información primaria y secundaria. El análisis se centró tanto a nivel del discurso como de las prácticas observadas; por lo que se aplicaron entrevistas, realizaron historias educacionales y protocolos de observación a los distintos agentes educativos aymara y no aymara. Una parte fundamental del proceso de investigación se centró en el estudio de los textos escolares, aplicándose en éstos análisis de contenido. Por otra parte, también se recurrió a documentación existente en los servicios que sin dudas ha generado relevantes consecuencias socioculturales en esta población indígena. ${ }^{5}$

En términos formales, los contenidos se han organizado en cuatro partes. La primera, de carácter contextual, entrega antecedentes históricos generales sobre la presencia de la escuela formal en el sector aymara del norte de Chile; continuamos con la exposición de información proporcionada por los propios maestros/as y la experiencia escolar de mujeres y hombres aymara; luego, exponemos los resultados obtenidos con el análisis de contenidos de los textos de estudio, para concluir con una breve caracterización de la situación educacional por género y reflexiones finales.

educacionales regionales, con el fin de caracterizar las dinámicas educativas del sector altiplánico.

Las entrevista fueron aplicadas a 30 alumnos, hombres y mujeres del altiplano sur y norte, de tres generaciones distintas, siguiendo el criterio básico de haber estudiado durante la implementación de los tres principales planes y programas educativos estatales rurales (1930-1965/1965-1977/ 1977-1990); 20 padres y apoderados, con criterios similares al anterior; y 14 profesores rurales, del altiplano sur y norte, en labor docente durante cada una de las décadas del lapso considerado. Las historias educacionales se realizaron a ocho informantes, hombres y mujeres, jóvenes y adultos del sector altiplánico sur y norte. Por su parte, las observaciones, se efectuaron en dos escuelas rurales (altiplano norte, altos de Arica; altiplano sur, altos de Iquique).

5 Nos interesa aclarar que estamos conscientes que las características culturales que actualmente presenta la sociedad aymara del norte de Chile y que la diferencia de la sociedad chileno-mestiza es, sin dudas, producto del pasado, de la herencia cultural propia, como también en gran parte de los acomodos y pérdidas que los habitantes de este territorio han debido realizar para reproducirse en contextos de dominación sucesiva (inka, hispana, peruana y chilena). Así, su identidad depende de la relación que han tenido con los procesos sociales impulsados por los Estados y sociedad colonial y nacional, siendo importante no solo los contenidos culturales sino los límites o fronteras, mantenidas por adscripción así como por recursos externos, entre los que destaca la permanente diferenciación que hace la sociedad regional. Esta diferenciación, en nuestro país, ha sido negativa ya que tanto la sociedad regional como el Estado han actuado bajo el supuesto de que la diferencia cultural constituye un obstáculo para los proyectos de modernización y homogenización cultural. En este escenario, consideramos que la escuela y los procesos de educación "formal" han influido significativamente, generando consecuencias socioculturales relevantes en la población en estudio. Lo anterior, sin desconocer que la cultura cambia, se transforma y los sujetos tienen capacidad de agencia frente a nuevas realidades. 


\section{* Instalación de la escuela en las COMUNIDADES RURALES DEL ALTIPLANO CHILENO}

No existe consenso ni fechas exactas entre los estudiosos del tema para definir el momento preciso en que se inicia el proceso de ampliación de la educación formal rural hacia el sector altiplánico chileno. Se menciona la década de 1930 como el advenimiento de la escuela formal, ya no como un elemento de adoctrinamiento religioso para la población indígena (Córdova 1982: 20), sino como una acción planificada desde el Estado (Podestá 1981: 151). Sobre lo que sí hay acuerdo, es que se marcarían dos momentos en el que la educación llega al altiplano: uno vinculado a iniciativas no estatales (enviados de la Iglesia, profesores particulares pagados por la propia población del sector); y el otro, por la presencia del Estado chileno, a través de la construcción de establecimientos educacionales formales (Echeverría 1999; Tudela 1993-1994; Córdova 1982).

La mayoría de las investigaciones que abordan el rol de la Escuela Nacional en el norte de Chile describen cómo ésta contribuyó al proceso de chilenización de las provincias que se anexaron después de la Guerra del Pacífico, siendo su objetivo central establecer el dominio territorial y político de Tarapacá (Podestá 1981; Gundermann 1986; van Kessel 1992; Echeverría 1999; Tudela 19931994; González 2002; Díaz y Ruz 2009).

Los antecedentes históricos señalan que las primeras escuelas se habrían instalado en el área rural, de la antigua I Región de Tarapacá, en las zonas precordilleranas. La apertura de establecimientos de enseñanza básica por parte del Estado en la zona altiplánica es un tanto más tardía, fijándose su presencia entre los años 1940 y 1950, motivada por solicitudes realizadas por las propias familias aymara (Gundermann 1986; Echeverría 1999; González 1995).

Este interés por acceder a la enseñanza escolar básica no fue homogéneo en las comunidades (Gundermann 1985: 7; Gundermann et al. 2011: 81-82; González 2002: 28), sugiriéndose que quienes tomaron la iniciativa de hacer las peticiones ante las autoridades locales fueron personas que habían establecido contacto con valles y ciudades, a través, principalmente, del trabajo temporal.
Inicialmente las prestaciones estatales fueron parciales. Los comuneros debían realizar contribuciones en dinero o trabajo para la edificación de los precarios establecimientos, apoyar el traslado de materiales que ellos mismos donaban, y pagar monetariamente la labor docente que, además, implicaba la ayuda con alimentos a los/as profesores/as. Esta situación trajo dificultades y diferencias dentro de las comunidades, particularmente entre aquellas familias de menos recursos, que no podían entregar el aporte requerido, y los ancianos, que no comprendían la importancia asignada a la educación.

El panorama descrito brevemente en este período nos muestra como, inicialmente, el ingreso a la enseñanza fue diferenciada por sectores geográficos (fundamentalmente entre precordillera y altiplano) y por las características socioeconómicas de las familias, debido a los costos implicados que suponían los aportes en dinero o trabajo y/o demanda de mano de obra infantil. También fue distinto para mujeres y hombres, ya que ellas ingresan tardíamente en relación a ellos, constatación que se puede ver claramente reflejada en estudios que indican que mientras las mujeres aymaras mayores de 25 años tienen un promedio de 0,8 años de escolaridad, los hombres sobre esa misma edad presentan 1,8 años de escuela (Gundermann,1986). Los últimos censos de población (1992 y 2002) son claros también en demostrar la distancia en años de escolaridad entre ambos géneros, así como en los cambios que han ocurrido entre las generaciones. El Censo de 1992 nos muestra que el promedio de años de estudio de la población de la comuna de General Lagos es de 4,16 años para los hombres, mientras que para las mujeres es 2,99. Para la comuna de Colchane, los hombres alcanzan 5,42 y las mujeres 3,98. Entre los 15 y los 70 años de edad esta fuente indica una gradiente espectacular que va de los 7,40 hasta 0,27 años para los hombres y desde 6,69 hasta 0,07 años para las mujeres en General Lagos y en Colchane desde 6,89 hasta 1,24 años para los hombres y desde 6,39 hasta 0 años para las mujeres.

Vemos así, que a mayor edad más amplia es la brecha entre mujeres y hombres aymaras; siendo distinta la situación en los estratos de edad más jóvenes, donde la diferencia disminuye. Este aumento de los niveles de escolaridad femenina tiene distintas explicaciones, pero una que los/as entrevistasdos/as destacan es la Ley sobre "instrucción primaria obligatoria" -acaecida en el marco de la reforma 
educacional del gobierno del presidente Frei Montalva (1964-1970) - que expresaba el compromiso estatal de alcanzar la cobertura universal de este nivel (Cox, 1997), y que en la zona en estudio fue aplicada con ayuda de la fuerza pública (Carabineros). Así, era frecuente que la resistencia de los padres por enviar a las hijas a la escuela fuese controlada por la presión policial solicitada en muchos casos por los/as maestros/as. A inicios de la década de 1980, con la creación de las Escuelas de Concentración Fronteriza en la precordillera andina (Putre y Ticnamar) y en el altiplano (Visviri, Colchane, Cariquima) (Gundermann et al. 2011: 87-88), esta presión fue ejercida para que las mujeres terminaran la enseñanza básica, de ocho años, ya que normalmente estudiaban hasta cuarto año básico y muy pocas hasta sexto año básico. Otro aspecto que varía sustancialmente a través del tiempo es la edad de ingreso, siendo común escuchar a los/as maestros/as señalar que antes de los años ochenta, además de que el número de alumnos/as era bajo, se presentaban edades avanzadas en los primeros años de enseñanza, cuestión que se agudizaba en el caso de las mujeres.

Otra situación que vale destacar y en la que tanto las fuentes primarias como secundarias coinciden, es el hecho que la Escuela Nacional ha actuado como agente de integración y asimilación de la población aymara rural, al transmitir conocimientos, costumbres y capacitación basados en modelos urbanos de vida, en desmedro de la cultura tradicional aymara (Echeverría 1999, Gundermann 1985, Tudela y González 2002, Gundermann et al. 2011). En palabras de González S.: "El currículum nacional no diferenció grupos ni culturas, provocando una homogenización del escolar chileno, herramienta poderosa para la asimilación. Así, el Estado no solamente ejerció legítimamente el poder represivo sino también su poder ideológico" (González 2002: 72).

Por otra parte, también existe consenso en que uno de los problemas centrales en este proceso de enseñanza y aprendizaje fue el de la comunicación debido a la lengua. La escuela basada en la lengua castellana, con larga tradición escrita, contrasta con la lengua aymara, con larga tradición oral (Gundermann 1985; Mamani 1985). Los profesores resaltan la falta de dominio de la lengua castellana como una limitante en su trabajo, situación que evidentemente se agrava en las estudiantes mujeres, lo que las lleva a altos niveles de repitencia. La dificultad por el mal manejo del castellano se presentaba durante los tres primeros años, situación que con el tiempo fue cambiando. A partir de los años ochenta, el uso de este idioma se hizo más frecuente en el contexto familiar y social, hablándose de una tendencia hacia el abandono del aymara como lengua materna. Gundermann (1985) señala que en 1985 la mayoría de la generación adulta y anciana y más de un $40050 \%$ de la generación joven (hasta los 20 años) tuvo al aymara como lengua materna. Los demás tienen por lengua de "cuna" el castellano.

Las dificultades comunicacionales para los/as maestros/ as se expresaban en la necesidad de reforzar permanentemente la enseñanza del castellano durante toda la enseñanza básica. Debían adaptar los programas utilizando diversas estrategias. Todos concuerdan en la inadecuación de los mismos al sector, tanto por las diferencias socio-étnicas como por las precarias condiciones de infraestructura disponibles. De acuerdo a los testimonios de los profesores, el alto nivel de ausentismo escolar que se presentaba también acarreaba dificultades en los resultados de aprendizaje. Entre las razones que enuncian, se halla también la necesidad de fuerza de trabajo para cumplir con las tareas productivas en ciertos períodos del año. La ausencia de los menores del trabajo familiar no significaba que los padres no desearan enviar a sus hijos e hijas a la escuela, más bien el reclamo se orientaba a un cambio en la calendarización de las actividades escolares.

\section{* Los profesores como agentes de CAMbio}

Con el objeto de obtener la visión de los propios maestros/ as de escuela sobre el proceso educativo se entrevistó a profesores/as que ejercieron en el sector rural, representando cada década considerada en el estudio; $y$ a maestros/as que ejercieron en el sector altiplánico sur hasta la década de 1960. En general, los/as entrevistados/as fueron consultados acerca de la realización de sus estudios docentes, su propia trayectoria, las características de sus alumnos/as, las particularidades de los programas y de la enseñanza, la relación con los/as alumnos/as y la comunidad, los principales problemas en su labor y los motivos de su retiro.

Los profesores que ejercieron en comunidades rurales durante el período contemplado, fueron capacitados para desempeñarse en escuelas urbanas. En general, se trató de hombres jóvenes que necesitaban desarrollarse labo- 
ralmente. Los motivos para ejercer la docencia rural caen dentro de lo circunstancial y, en general, no obedeció a un deseo personal, por lo que no significó un compromiso verdadero y definitivo con esta actividad. Muchos de ellos no encuentran otra alternativa laboral y esperan permanecer poco tiempo en el sector, hasta que encuentren vacantes en la ciudad.

Además de su labor en la escuela, los/as profesores/as cumplieron un importante papel como agentes de cambios dentro de la comunidad al ser portadores/as de nuevas costumbres y al incorporarlas, muchas veces, como un ítem más dentro de los programas educacionales.

A través de los programas, los/as profesores/as formados para la enseñanza en las ciudades y con bajos niveles de información acerca de las diferencias socioculturales, voluntaria e involuntariamente cuestionan la forma de vida aymara, desvinculando a los estudiantes de su medio. Así, resulta "natural" que la escuela sea un "modelo de urbanidad", en la que se olvida el ambiente, actividades e ideas aymara. (Gundermann 1885:22)

La capacidad de intervención de los/as profesores/as sobre las ideas de desempeño futuro en el alumnado son decisivas. La imagen del/a maestro/a como persona dotada de conocimientos y experiencias superiores estaba en el pasado fuertemente arraigada entre los comuneros aymara, cuestión que persiste en la actualidad. Se declaran dispuestos a influir sobre sus alumnos/as para que cambien y adquieran el máximo de conocimientos hasta alcanzar un oficio o profesión calificada desde un punto de vista urbano. En este sentido, el tipo de persona que aspiran formar en los niños/as aymara no se aparta del de un niño/a de otras zonas del país. Su búsqueda consiste en dotarles de capacidades para "desenvolverse en la vida como persona útil". Se espera favorecer su desarrollo en medios urbanos, ampliar habilidades de expresión en lengua castellana, disminuir su supuesto carácter tímido o cohibido, propiciar una personalidad más agresiva. En suma, "despertar al niño" de la condición social y cultural indígena, que le favorecería muy poco, para asumir las diversas posibilidades abiertas al progreso económico y social fuera del sector rural, especialmente en el altiplano. El hecho que migren y al menos trabajen como braceros y peones en valles bajos es considerado un avance inicial importante.
Los profesores aprecian con claridad que poco o ningún efecto tiene la formación que entregan en crear raigambre o capacitación campesina y que por añadidura, gran parte de sus alumnos/as y los jóvenes ya escolarizados aspiran decididamente a abandonar sus lugares de origen. Son los adultos y ancianos quienes no se resignan y ofrecen resistencia a la idea del abandono de la comunidad, de los rebaños y de las chacras. Algunos asumen que son una causa eficiente en la diferencia generacional: "se van viendo los cambios" al tenor de su influencia. Otros disminuyen el peso de su intervención atribuyéndola al aumento de la integración, producto de una mejora en los medios de transporte y las comunicaciones entre las distintas zonas de la región, la que influiría en que los/as jóvenes aspiren a cambios y a una vida moderna, o más directamente a la intervención de otros agentes externos ajenos a la escuela.

El trabajo campesino les parece mal retribuido y sin ninguna posibilidad de prosperar. De allí que buena parte de sus esfuerzos estén destinados a dirigir a los/as jóvenes en la búsqueda de nuevos horizontes. Se convencen de ello a partir de sus observaciones e interpretaciones de la pobreza y "primitividad" campesina.

Otra función de los profesores es la acción "civilizatoria". Durante su permanencia en los pueblos "había que cambiar los valores, porque tenían pocos valores. El mundo de ellos es muy reducido, solamente su ganado, su casa, salir en la mañana al pastoreo, volver en la noche a comer y se acabó". Esto los transforma en agentes conscientes del cambio cultural. Más allá de preocuparse por exaltar valores patrios, convence a sus alumnos/as para que prosigan estudios, estimula el aseo personal, recomienda normas de convivencia social, inculca el respeto a las autoridades, etc. Se les considera también activos impulsores de obras de adelanto de las aldeas, favorecedores de la concentración residencial en áreas ganaderas de hábitat disperso. Con frecuencia, parecen preocupados por detalles menores, pero significativos como impacto psicológico en los individuos: "Las niñas usaban pantalón, la media, la ojota y más encima la pollera. Y esos hábitos se los cambié. Las niñitas me iban con pantalón o me iban con vestidos, pero no con las dos cosas. Se veían ridículas. Y después con los años los demás niños del pueblo de al lado que andaban vestidos así, se veían mal. Ellas mismas se empezaron a dar cuenta de esos cambios, acá no, ellas con su jumper o su vestido diferente y el hombre no usa el yucho". 
La transmisión de valores por parte de los/as profesores/ as que contribuyeran a cambiar la forma de vida aymara es reconocida también por los campesinos: "Los profesores me decían: ustedes tienen que salir de la chala, de esa ropa tejida que usan, de los gorros de lana, ustedes tienen que cambiar, no tienen que ser iguales que los viejos, tienen que cambiar de lo que son. Tienen que irse a la ciudad, vivir cómodos, vivir bien".

Los maestros también participaron en la alfabetización de los adultos e introdujeron nuevas formas de vida y pensamiento: "Yo enseñé a leer a algunas personas, a firmar a los más viejitos, que las personas pudieran tener un poco más de conocimiento, de orden, de aseo. Todas esas cosas. Incluso hice labores en los mismos hogares. Yo los iba a visitar y la casa estaba limpia. Se vieron los cambios. Ahora mi misma señora les enseñó prácticamente a cocinar. Cuando venía la gente enseñaba [a] hacer otro tipo de comida diferente a la papa chuño, el arroz, la carne y el charqui. Empezamos a hacer una labor... prácticamente a enseñarles muchas cosas que ellos no conocían. La gente adulta tiene ese concepto de conocimiento vulgar de que las cosas obedecen a ciertos dioses o mallku, pero cuando se les muestra algo al niño, cientificamente quedan bastante admirados y quedan dispuestos a recibir más".

Es así que el rol que desempeña el profesor dentro de la comunidad es fundamental considerando que es visto con admiración y él mismo opera como modelo ideal. El maestro, asimismo, tiende a cambiar, muchas veces voluntariamente, desde los valores estéticos hasta la proyección que sus alumnos tienen para sí como personas.

\section{* LAS expectativas de madres y padres}

Las entrevistas realizadas a mujeres y hombres de la zona altiplánica señalan marcadas diferencias entre los géneros - no así generacionales - en cuanto a la visión de la escuela, los estudios y el aprendizaje. Se rescatan importantes discordancias entre las apreciaciones respecto de sus propias experiencias y las que desean para sus hijos/as.

Según sus expresiones, durante los primeros tiempos de la escuela, la comunidad se resistía a enviar a los niños/ as a clases, por la sustracción de fuerza de trabajo que significaba. Tradicionalmente, los niños han ocupado un lugar importante como colaboradores de las tareas de la unidad doméstica (actividades domésticas y productivas). Sin el manejo de la lengua castellana, la escuela resulta- ba demasiado compleja y distante. A lo largo del tiempo, estas dificultades se relativizan, cada vez más los padres y madres esperan educar a sus hijos/as, entendiendo que un futuro mejor para ellos/as se encuentra en la ciudad. Por ello, las mejores herramientas para desenvolverse en un medio urbano las pueden adquirir a través de la escuela. El proceso de desvalorización de su propio sistema de vida y de su lengua los lleva a pensar que el progreso y el desarrollo se encuentran en la ciudad. Comprenden que quien debe proveer al hogar es el hombre, por lo que debe emigrar en busca de un trabajo asalariado que permita solventar los cada vez mayores patrones de consumo monetarizados. Las mujeres deben encargarse de los niños/ as y del cuidado del hogar. Visto de esta manera, es más importante la educación en varones que en mujeres. En las generaciones más antiguas, los niveles de escolaridad de ellas eran menores que los de ellos y las mujeres ingresaban más tardíamente al sistema escolar. Actualmente, existe una tendencia, expresada a través de las entrevistas, a comprender como necesaria la escolaridad para ambos, aunque se continúa esperando que sean los hombres los que logren mayores niveles de educación.

Durante los primeros tiempos, dentro de la familia se daba prioridad a la educación de los hijos por sobre las hijas, arguyendo que serían ellos los que más tarde debían sostener una familia, al contrario de las mujeres que debían aspirar a casarse, por lo que la instrucción escolar no era necesaria. Por esta misma razón, los varones emigraban hacia valles y ciudades a continuar su educación -terminar primaria y continuar secundaria- mientras que las niñas, terminado el ciclo primario (muchas veces solo hasta cuarto básico), daban fin a su educación formal. Ellas confiesan considerar innecesarios tantos años de escolaridad para sí mismas, aunque en estos nuevos tiempos sí aspiren a ver educadas a sus hijas, argumentando que no desean para ellas la vida campesina, por considerarla "dura" en contraposición a los trabajos más livianos que una mujer podría desarrollar si estudia.

A medida que la escuela se va posicionando dentro de la vida social aymara, la resistencia hacia ella va también cediendo y la comunidad comienza a considerarla una vía de desarrollo y de ascenso social, además de una forma de lograr mejores expectativas de vida. Tanto mujeres como hombres coinciden en apreciar la educación como una manera de movilidad social fundamentalmente en el 
sector urbano y como forma de lograr un mejor posicionamiento y valoración social.

La escuela significa, de algún modo, aprender cosas que más tarde serán de utilidad para el modo de vida en la ciudad. De esta forma, se convierte en algo necesario, más para hombres que para mujeres, pues se presume que serán ellos los que inevitablemente deberán emigrar. Así, un tema relevante resulta ser la migración que, en la generación más antigua, se produce no por su propia educación, sino por la de sus hijas/os; solo en la generación más reciente, hay migraciones por estudios propios.

Hombres y mujeres aymaras relacionan la educación formal con un modo de vida menos sacrificado, con trabajos más livianos. Muchos, de las generaciones adultas expresan no mandar a sus hijos a pastear ganado, ni hilar o tejer, porque no desean estimular esta forma de vida en ellos, sino por el contrario, solo quieren verlos dedicados a sus estudios. A la escuela se le atribuye condiciones no solo educativas en términos académicos sino formativas de hábitos.

Desde el punto de vista del trabajo, actualmente, al preguntar sobre las actividades de mujeres y hombres, tanto entrevistadas como entrevistados señalan que solo los hombres trabajan, dedicándose las mujeres a la crianza de los niños y el trabajo doméstico. Se dice que ellas no trabajan, aun cuando describen entre sus actividades diarias cargar pasto; acarrear agua y leña; pastear cordero, ovejas, llamos; lavar (mantillas y ropa), cocinar, moler y tostar quínoa; cuidar a los menores; hacer aseo; hilar, torcer, tejer; trabajar la tierra; ayudar en fiestas, etc.

Identificamos en estas expresiones una desvalorización del trabajo de las mujeres y una valoración mayor de los ingresos que generan los hombres. El trabajo campesino de las mujeres comienza a ser considerado no trabajo y las actividades que realiza en su hogar urbano sufren la misma connotación. Esto nos indica que la idea que han construido sobre lo que es el "trabajo" coincide con el concepto de trabajo remunerado.

\section{* Experiencia escolar de mujeres y hombres}

Para conocer lo que mujeres y hombres aymaras del sector altiplánico norte y sur, piensan en torno a la escuela y las diferencias que existen entre ambos, realizamos historias educacionales.

Las diferencias más claras que observamos en cuanto a su experiencia escolar se expresa en los proyectos de vida que han ido generando en este proceso: mientras los hombres conciben la educación como un medio para lograr una mejor posición social y un trabajo mejor remunerado, las mujeres tienden a verla como un fin en sí mismo a través del cual incorporan herramientas para desenvolverse mejor en un entorno distinto, pero en general no como un medio de ascenso social. Por esta razón valoran la escuela como una institución formadora de hábitos.

De esta manera serán ellos los que asuman como obligación salir a buscar trabajo fuera de la comunidad, mientras que ellas se quedarán en sus lugares de origen cuidando el patrimonio familiar (Tabla 1). Actualmente, sin embargo, las generaciones más jóvenes de ambos sexos parecen creer que el futuro se encuentra en las ciudades.

\section{* Los textos escolares}

Tres reformas educacionales se sucedieron durante el período contemplado en esta investigación, pero esto, en la práctica, no significó grandes modificaciones en los libros y programas de estudio, que en rigor, fueron sustancialmente los mismos a lo largo del tiempo.

Asumimos que los textos escolares son un medio institucionalizado utilizado por el aparato escolar para instruiry educar. Transmiten contenidos normativos y valorativos, moldean actitudes y comportamientos de los alumnos en una etapa clave para la formación de la personalidad. A través de ellos, los alumnos aprenden lo que se espera de niños y niñas de su edad, lo que está bien y lo que está mal. Además, proveen modelos de rol, imágenes de lo que pueden y deben ser cuando grandes. No olvidemos que se trata de modelos idealizados, criaturas "perfectas", llenas de virtudes que muestran a los escolares lo que ellos mismos deberían ser (Wainerman y de Raijman 1987). Por lo mismo, nos proporcionan una fuente invaluable de análisis para develar los sistemas básicos de valores de la sociedad que los produce. 


\begin{tabular}{|c|c|}
\hline Mujeres & Hombres \\
\hline Asisten a clases para aprender a leer y escribir. & $\begin{array}{l}\text { Asisten a clases para aprender a desenvolverse en la vida, para capacitarse para } \\
\text { acceder a un mejor trabajo. }\end{array}$ \\
\hline $\begin{array}{l}\text { No dan importancia a la educación para ellas mismas, pero sí para sus hijos } \\
\qquad \text { e hijas. }\end{array}$ & $\begin{array}{l}\text { Dan importancia a su propia educación. Se aspira a alcanzar la mayor cantidad de } \\
\text { años de escuela posibles, para proyectar una vida mejor para ellos y su familia. }\end{array}$ \\
\hline Se motiva imitando a sus hermanos estudiantes y por obligación. & Se motiva a conocer, aprender y salir del "atraso". \\
\hline $\begin{array}{l}\text { Presentan dificultades en el aprendizaje del castellano y reconocen falta de } \\
\text { ayuda familiar en el estudio. }\end{array}$ & Presentan buen manejo del castellano. \\
\hline La asignatura preferida es matemática. & Las asignaturas preferidas son matemática e historia. \\
\hline Personajes que destaca de los textos: campesinos. & Personajes que destaca de los textos: héroes patrios. \\
\hline $\begin{array}{c}\text { Valoración de la enseñanza: formación personal (aprender a comportarse, } \\
\text { vestirse y arreglarse), formadora de hábitos. }\end{array}$ & $\begin{array}{l}\text { Valorización de la enseñanza: posicionarse mejor en la sociedad mayor (aprender a } \\
\text { hablar castellano y tener "mejores ideas"). }\end{array}$ \\
\hline
\end{tabular}

Tabla 1. Experiencia escolar de mujeres y hombres.

\begin{tabular}{|c|c|c|}
\hline \multirow{2}{*}{ Fuera del hogar } & $\begin{array}{c}\text { Mujer } \\
\text { Vendedora, directora, nana, profesora, pastora, reina, } \\
\text { participante en las ceremonias religiosas }\end{array}$ & $\begin{array}{c}\text { General, profesor, doctor, inspector, guerrero, soldado, pastor, marino, payaso, } \\
\text { autoridad, abogado, maquinista (tren), campesino (ara, corta trigo, recoge } \\
\text { choclos), cazador, candidato al sindicato, organillero, cartero, mozo, músico, } \\
\text { obrero, electricista, policía-vendedor, jardinero, sereno, pescador, marinero, atleta, } \\
\text { pastor, rey, sacerdote, maestro, albañil, flautista, bandido, viaja, vota, corta leña, } \\
\text { trabaja la tierra (ara, riega, siega, recoge la papa) }\end{array}$ \\
\hline Dentro del hogar & $\begin{array}{c}\text { Preparación de comidas, preparación de remedios, servir } \\
\text { cuidar a los niños, preparar los niños para el colegio, hacer las } \\
\text { compras, administrar el dinero de hogar, atender al esposo, } \\
\text { asear la casa, coser, planchar, zurcir }\end{array}$ & $\begin{array}{c}\text { Proveer a la familia, decidir los gastos del hogar, brindar en las fiestas, realizar los } \\
\text { trabajos más "pesados" de la casa }\end{array}$ \\
\hline
\end{tabular}

Tabla 2. Resumen de actividades desarrolladas fuera del hogar por hombres y mujeres.

La selección de los textos se basó en los citados por profesores/as entrevistados/as que desempeñaron y/o desempeñaban una labor docente en escuelas rurales del altiplano. Indagamos acerca de las ideas y los contenidos valóricos referidos a la división del trabajo por género.

Los libros usados en el área rural han sido los mismos utilizados en el sector urbano. Apenas uno de ellos fue diseñado especialmente para la población del sector altiplánico. Destácase también otro libro utilizado como apresto para adultos, cuyo contexto se desenvuelve en un entorno rural, pero no andino. Lo usual, según los/as entrevistados/as, era que ellos/as mismos/as decidieran los textos que más les acomodaban para desempeñar su labor.
Los ejemplares seleccionados son silabarios y libros de lectura. Comenzamos con el análisis de los primeros, continuando con los textos de lectura siguiendo el orden cronológico de su primera edición. Aunque algunos de estos fueron editados años antes del período que nos interesa, se utilizaron con frecuencia durante éste. Los títulos son los siguientes:

- Silabario Matte. Primera edición, 1902.

- Silabario hispanoamericano. Primera edición, 1945.

- Silabario para adultos "Mi Tierra". Primera edición, 1946. 


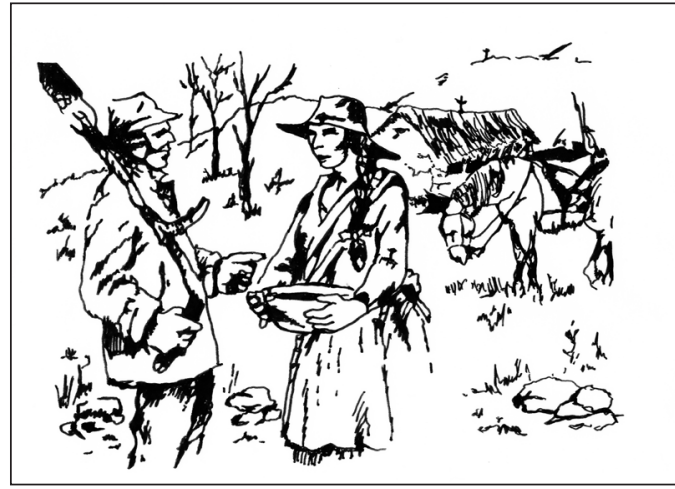

Figura 1. Los padres (Díaz et al. 1985:50).

- Lea en colores. Primera edición, 1946.

- Marka Masi (Somos del mismo pueblo). Primera edición, 1985.

- El nuevo lector americano. Primera edición, 1928.

- El lector chileno. Primera edición, 1928.

Los objetivos específicos definidos para el análisis de contenido fueron los siguientes:

1. Identificar las actividades asociadas a hombres y mujeres.

2. Identificar las capacidades físicas y psicológicas asociadas a hombres y mujeres.

3. Comparar las ideas acerca de las actividades y capacidades de hombres y mujeres y acerca de lo femenino y lo masculino.

4. Identificar variaciones a partir de los años de edición de los textos escolares.

Tomando en consideración el diseño general de los textos, organizamos la información en torno a tres unidades de análisis. Primero, elegimos el tema o fragmento de cada uno de los libros que expresa una idea central, tomándose en algunos casos frases, párrafos y texto escrito reforzado por imágenes. Se definieron diez categorías analíticas a fin de extraer los mensajes en cada tema, para lo cual se construyó una base de datos que, posteriormente, fue trabajada tomando cada texto como unidad. Como paso final, se consideró toda la muestra en su conjunto para obtener totales significantes.

\section{* Mujeres y hombres, lo femenino y LO MASCULINO EN LOS TEXTOS}

El análisis del material muestra las asociaciones de los géneros a espacios específicos de la vida social y política (Tabla 2). Las actividades para las mujeres son diversas y amplias dentro del hogar pero escasas y reducidas a su rol de agentes socializadores en el ámbito público. En contraste, a los hombres, a quienes se les asocia a una gran diversidad de oficios y actividades fuera del hogar, al interior de éste se vinculan únicamente con su rol de proveedor.

De la Tabla 2 se desprende que las actividades desempeñadas por los hombres fuera del ámbito hogareño que se exhiben en los textos superan ampliamente a las desarrolladas por las mujeres. Existe una diversidad de oficios, profesiones y actividades que se presentan como modelos a los niños, mientras que las niñas ven reducidas las actividades de las mujeres a unas cuantas profesiones que resultan ser muchas veces una extensión de la maternidad o de servicio "a otros". Es interesante resaltar que, como mensaje, puede resultar más importante la omisión que se hace de las tantas actividades, oficios y profesiones que realmente realizan las mujeres en la vida diaria y que no son visualizadas por la sociedad. Hay que recordar que estos textos hasta hace algunos años atrás (19801990) se continuaban usando en el sector.

Identificamos un bajo número de actividades asociadas al trabajo campesino. Tres de los textos analizados hacen mención a este tipo de trabajo ("Mi Tierra", "Lector chileno", "Marka Masi"), y en su totalidad, asocian las labores de la tierra con los hombres, mostrando a las mujeres en la cocina y el servicio de las comidas (Figuras 1-3).

Únicamente Marka Masi presenta dentro de sus imágenes a una mujer pasteando ovejas y llamas. Esto, además de indicar una invisibilidad del aporte de las mujeres a la economía del país y por lo tanto una subvaloración del mismo, nos revela una clara orientación de 


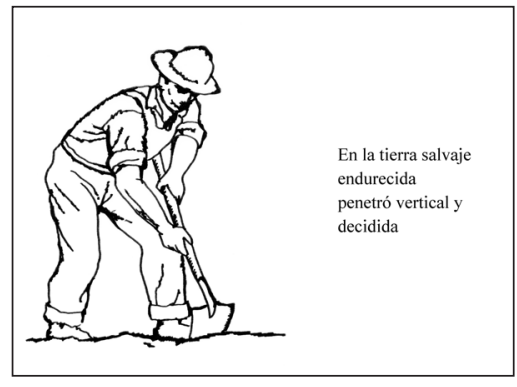

Figura 2. La pala (Guzmán 1928: 49).



Figura 3. El trabajo de mamá (Labarca 1928: 22).

\begin{tabular}{|c|c|}
\hline Mujeres & Hombres \\
\hline $\begin{array}{c}\text { Ser madre, tejer, estudiar, leer y escribir, coser, ayudar a mamá en } \\
\text { las labores domésticas, amar a los hijos, ser trabajadora, aprender a } \\
\text { servir, barrer, preparar las comidas. } \\
\text { Juegos: muñecas, rondas, luche }\end{array}$ & $\begin{array}{c}\text { Proteger a los hermanos menores, defender a la mamá, cantar, dibujar, ser profesor, } \\
\text { médico o abogado, hacer el servicio militar, inscribirse para votar, estudiar una } \\
\text { carrera, ganarse el pan, proveer el pan, ser soldado, marino, militar, minero, } \\
\text { bombero, carpintero, scout, ser trabajador, imaginar aventuras, ser responsable, ser } \\
\text { un gran hombre, ser músico, pastor, ser el futuro del país. } \\
\text { Juegos: trenes, bolitas, barcos, aviones, autos, buques }\end{array}$ \\
\hline
\end{tabular}

Tabla 3. Resumen de actividades estimuladas para hombres y mujeres.

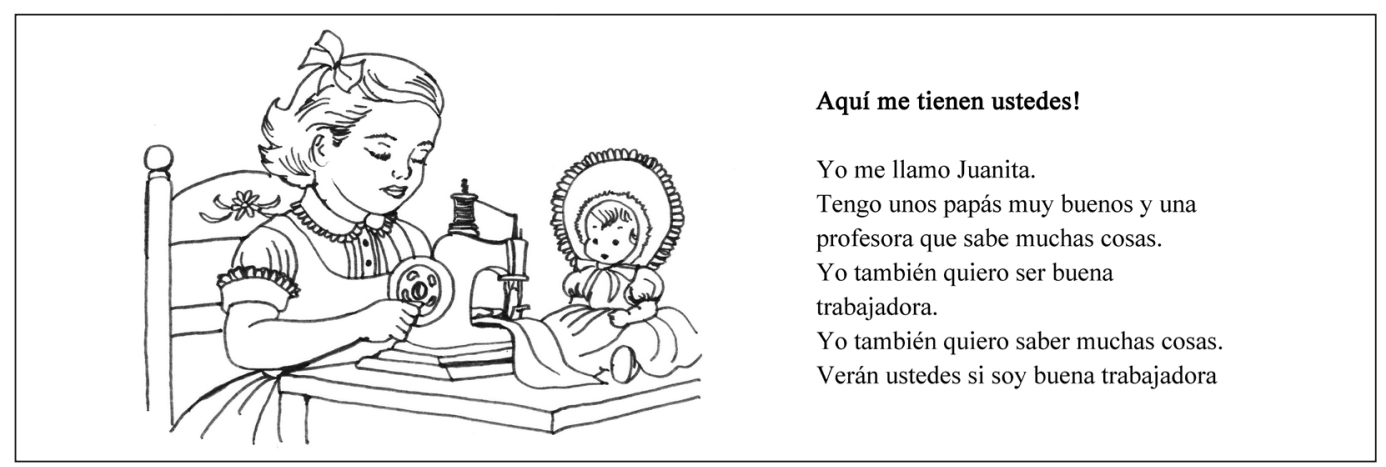

Figura 4. Juanita (Guzmán 1928: 18).

los textos a reforzar las actividades que se desempeñan en el espacio urbano.

Entre las actividades dentro del hogar registradas, verificamos un gran contraste entre lo identificado para hombres y mujeres (Tabla 3). Mientras que las mujeres se ocupan de la totalidad del trabajo doméstico y cuidado de los niños, el hombre es resaltado únicamente en su rol de proveedor.
En cuanto a las actividades estimuladas para mujeres y hombres se destaca por la fuerza con que aparece en los distintos textos, para las mujeres el rol de madre aparece como único proyecto de vida para las niñas (Figura 4). La exaltación de lo materno sin su contraparte en el hombre, deja las tareas vinculadas a los hijos e hijas en manos de las mujeres únicamente, atribuyéndole un carácter natural dentro del ordenamiento social. Los juegos que se destacan para ellas las preparan en este sentido. 


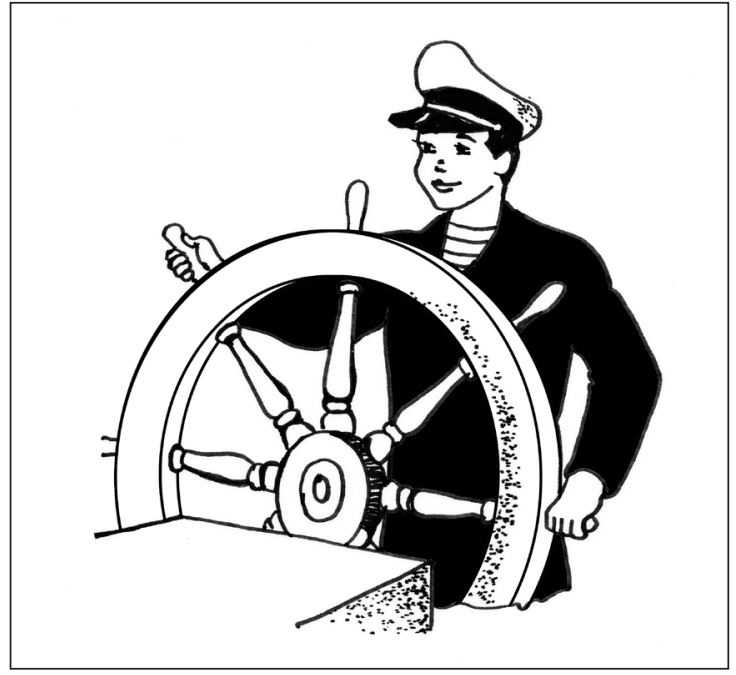

Figura 5. El niño que quiere ser marinero (Labarca 1928: 107).

Los varones son estimulados a desarrollar actividades recreativas (Figura 5), son incentivados a estudiar carreras profesionales o aprender un oficio y se refuerza la participación social, lo que está directamente relacionado con el rol de proveedor que se le adjudica constantemente.

Se recalca para ellos como un "deber" la protección y defensa de las/os hermanas/os menores y de la madre, al igual que ser responsables y representantes de la familia. Sus actividades son mucho más diversas y creativas. Los proyectos de vida que se presentan para ellos son más grandilocuentes y gravitantes.

Si abordamos el problema desde el punto de vista de las cualidades psicológicas y capacidades físicas atribuidas a mujeres y hombres (Tabla 4), encontramos diferencias sustanciales. Los niños realizan actividades más dinámicas y se los haya, a menudo, asociados a cualidades como valiente, fuerte y seguro. Ellas, en cambio, están señaladas como pasivas, cariñosas y sensibles.

Podemos develar así los estereotipos de género que operan para la construcción de lo femenino y lo masculino en los textos escolares. Una de las características de ellos es su exclusión, es decir, las asignaciones para el primero no son apropiadas para el segundo. Todas

\begin{tabular}{|c|c|}
\hline Mujer & Hombre \\
\hline $\begin{array}{c}\text { Pasiva, menuda, amorosa, modesta, } \\
\text { agradecida, buena amiga, paciente, } \\
\text { tierna, bella, obediente, dulce, } \\
\text { hospitalaria }\end{array}$ & $\begin{array}{c}\text { Valiente, fuerte, activo, generoso, } \\
\text { exitoso, sereno, seguro, buen } \\
\text { alumno }\end{array}$ \\
\hline
\end{tabular}

Tabla 4. Resumen de cualidades y capacidades físicas y psicológicas asociadas a hombres y mujeres.

las actividades dentro del hogar relacionadas con las mujeres no aparecen en el caso de los hombres y aquellas asociadas a los hombres en este ámbito no se presentan para las mujeres. Fuera del hogar, los términos masculinos -que no tienen presencia en el caso de las mujeres - son más variados: general, guerrero, soldado, cartero, abogado, etc. En esta misma línea, las actividades estimuladas repiten la diversidad para los hombres y restringen a las mujeres a la maternidad y a las labores domésticas, lo cual orienta a los varones a una mayor capacidad de invención y creatividad en el ámbito público, mientras que esta capacidad se reduce a lo mínimo para lo doméstico.

Si bien el texto "Marka Masi" muestra mayor equilibrio entre las asociaciones, las orientaciones también son excluyentes. Las diferencias son más marcadas dentro que afuera del hogar. Las distinciones se expresan principalmente en el ámbito de la estimulación al orientar a los hombres a una gama más diversa de actividades. La oposición se marca aquí, ampliando el quehacer de los hombres a los estudios y a ser el "futuro del país".

En cuanto al trabajo campesino, el análisis nos permite tomar cuenta del bajo número de actividades asociadas al mismo y la asociación subrayada para los hombres. Este ordenamiento nos expone nuevamente la tendencia a vincular menos a las mujeres que a los hombres con las actividades remuneradas no campesinas.

Los antecedentes expuestos señalan una marcada diferenciación entre los géneros. A pesar del largo período de uso de los textos seleccionados, no se observan cambios sustantivos en lo que respecta a la división sexual del trabajo. Notamos así una subvaloración del aporte de las mujeres a la economía y al desarrollo. 
Los contenidos de los textos, mayormente usados por los/as maestros/as rurales de las regiones administrativas primera y decimoquinta, durante el período de estudio se orientan a modelos de vida urbanos y a una distribución del trabajo excluyente. La exaltación de la maternidad como ideal femenino y la orientación de lo masculino al rol de proveedor del hogar y al espacio público, reduce a la mujer y al hombre solo a algunas de las muchas actividades que desempeñan en la vida real. Pero la escasa importancia asignada al trabajo del campo, como otra actividad económica, agudiza todavía más la exclusión de las mujeres de las labores productivas.

\section{* Los modelos de género en la escuela y LOS ROLES DE MUJERES Y HOMBRES AYMARA}

Considerando estudios anteriores sobre el ciclo vital de mujeres y hombres en las comunidades altiplánicas, ${ }^{6}$ que señalan una compleja distribución del trabajo dentro de la familia, podemos señalar que las mujeres cumplen un rol central en las tareas agrícolas y de pastoreo, y que el trabajo productivo forma parte central de su formación. Los hombres, aunque igualmente participan en ellas, se orientan al comercio y al transporte. Las actividades reproductivas, sin embargo, están en manos de las mujeres. De acuerdo a esta información, la distribución sexual del trabajo no es excluyente en el área productiva, más sí en la reproductiva.

Entre las diferencias destacadas en las prácticas escolares durante el período en estudio, se observan dos aspectos de interés. Por una parte, los hombres son los representantes sociopolíticos del hogar, por tanto las mujeres son representadas por ellos. Por otra, las mujeres abandonan más tempranamente la escuela que los hombres, para dedicarse a las actividades campesinas (textilería, ganadería, agricultura, comercio menor).

Por otra parte, si recordamos que las mujeres ingresan más tardíamente a la escuela, es posible asumir que los contenidos de los textos han sido más eficaces en hombres que en mujeres. En este sentido, es pertinente reconocer una diferenciación en los efectos de la socialización escolar en ambos géneros.

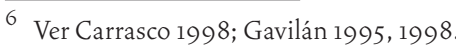

A partir de la información expuesta, podemos colegir que la formación escolar ha incidido en los cambios en la división sexual del trabajo. Si bien los procesos crecientes de mercantilización de la economía altiplánica cumplen un rol fundamental en las transformaciones socioeconómicas de las familias, los efectos de la socialización escolar contribuyen de una manera decisiva. Aun cuando es necesario analizar los procesos de apropiación de estos contenidos por parte de la población aymara, es posible sugerir que el sistema escolar ha sido más eficaz en hombres que en mujeres. La ausencia de los hombres jóvenes de las actividades productivas campesinas y su orientación al comercio y al transporte se relaciona con los resultados del análisis de textos.? En el caso de las mujeres, se observa cierta continuidad en su ciclo de vida. La salida temprana de la escuela y su inserción al trabajo facilita la aproximación al modelo de ser mujer en la comunidad. Sin embargo, al excluir a los hombres de las tareas reproductivas, éstas aumentan su trabajo y liberan a los hombres para buscar nuevas fuentes de ingreso. La maternidad, como único modelo de ser mujer, no se percibe en el quehacer cotidiano de las mujeres ya que, si bien son las responsables del cuidado infantil y esta condición da mayor estatus cuando ocurre dentro del matrimonio, el ser madre no excluye su responsabilidad en las tareas productivas.

\section{$*$ Los efectos diferenciados en hombres Y MUJERES}

La información acopiada da cuenta del importante rol de la escuela como agente de cambios. Es posible argumentar que a medida que se fue consolidando el sistema educacional en el área, el peso de los/as profesores/as va disminuyendo y los programas (y los textos) van adquiriendo mayor relevancia como instrumentos efectivos de formación valórica e ideológica. Es claro que antes de la década de 1950, en su etapa inicial, el mayor aislamiento de las comunidades, la lengua aymara como medio central de comunicación, las condiciones precarias de enseñanza, entre otros, hicieron del/a maestro/a rural una pieza clave. El carácter misionero, su contribución al proceso "civilizatorio" de una población con poca claridad en su nacionalidad, los/as sitúa como actores centrales

\footnotetext{
7 Gavilán y González 2002.
} 
del proceso de transformaciones ocurrido en las comunidades altiplánicas. El poder que ejercieron a partir del estatus concedido por el Estado y por las propias comunidades es ejercido no solo en el ámbito pedagógico ni tan solo en la comunidad educativa, sino en muchos aspectos de la vida social comunal.

Esta distinción entre "programas" y "maestros/as" es útil para evaluar el peso relativo que tienen los contenidos ideacionales de los primeros en los cambios del comportamiento y pensamiento de mujeres y hombres. Sin embargo, es evidente que profesores/as y programas corresponden a un único modelo cultural. Podemos, entonces, asumir que la eficacia de los programas educacionales en cuanto a los contenidos es menor en la primera etapa de consolidación de la escuela nacional. Asimismo, serán menos eficaces que en estudiantes de las ciudades de las regiones en estudio ( $\mathrm{XV}$ y I).

Los antecedentes expuestos permiten hipotetizar acerca del impacto diferencial de la escuela en mujeres y hombres. El ingreso más temprano de los hombres a la enseñanza escolar básica y sus mayores años de estudios ha implicado un mayor impacto en ellos que en las mujeres, quienes ingresan más tardíamente y tienen menos años de escolaridad. Los datos indican que la población masculina ha sido tempranamente influenciada por la escuela y que las mujeres experimentan esta influencia con posterioridad. De esta manera, es posible sostener que los contenidos ideacionales transmitidos por la escuela son más eficaces en los hombres que en las mujeres; lo que conduce a pensar que son los hombres jóvenes quienes lideran los cambios en la comunidad.

Los modelos ideales transmitidos por los/as maestros/ as, los programas y los textos no solo han preparado a los/as estudiantes para la vida urbana sino que han desvalorizado sistemáticamente la forma de vida campesina, han desprestigiado la cultura aymara y han negado su historia y conocimientos. Es precisamente en el rechazo del saber aymara, donde el sistema educacional ha tenido mayor eficacia.

La visión de ex estudiantes aymaras respecto de sus experiencias en la escuela muestra las diferencias en los efectos del sistema escolar. Mientras los hombres asumen la educación de manera instrumental para el tra- bajo y ascenso social, las mujeres se aproximan a ella como un medio para desenvolverse mejor en las actuales condiciones de vida de la comunidad. Ellos resaltan las herramientas entregadas para una mejor relación con la sociedad nacional; ellas dan mayor importancia a la formación de hábitos. Los héroes patrios se constituyen en modelos masculinos, mientras las mujeres no encuentran modelos de identificación femeninos; destacando en ese sentido como personajes atractivos a los campesinos.

Una de las consecuencias del proceso de socialización escolar ha sido su orientación a la migración, cuestión que ha afectado mayormente a los varones. Ya sea por continuar los estudios o por encontrar mejores condiciones de vida, los hombres han sido motivados a la búsqueda de posibilidades laborales en las ciudades o a actividades no campesinas en las comunidades.

Esta imposición incluye la transmisión de estereotipos de género. Los testimonios son elocuentes. Los/as maestros/as y los programas postulan modelos de ser mujer y ser hombre vigente en la sociedad chileno-urbana, los que presentan una división del trabajo excluyente. Esto los lleva a invisibilizar el aporte económico de las mujeres campesinas y a no comprender los ideales de género entre las familias aymara. Asimismo, la aplicación de formas de comportamiento diferenciado según estos patrones llevó a los/as estudiantes a incluir, dentro de sus propias conductas, nuevas actividades y nuevas ideas respecto de sus proyectos de género; lo cual no ocurrió con los maestros. Es decir, el proceso fue claramente unilateral.

La opción de los padres por educar a los hijos varones puede ser también una consecuencia del proceso de socialización impartido por la escuela. Recordemos que en la sociedad chilena durante la primera mitad del siglo $\mathrm{XX}$, la educación para las mujeres aún no se generalizaba. Por otro lado, la obligatoriedad del servicio militar implicaba mayores exigencias para los hombres en el manejo de las relaciones con la sociedad nacional. La asistencia escolar implicó la ausencia de los menores del trabajo familiar; mientras las niñas continuaron colaborando, aun siendo alumnas. Es posible asumir que la redistribución del trabajo en la unidad doméstica se realizó entre los demás integrantes. A medida que las mujeres van ingresando al sistema educacional se ha producido un aumento en sus niveles de escolaridad. 
¿Cómo se distribuyen las tareas productivas y reproductivas? o ¿quiénes reemplazan a los jóvenes?

\section{$*$ Reflexiones finales}

La incorporación de la escuela a la vida de las comunidades rurales del sector altiplánico del Norte Grande de Chile ha significado, en gran medida, la negación y desvalorización de la cultura aymara. Como agente de integración y asimilación, basada en modelos urbanos, la Escuela ha contribuido a la pérdida por parte de la sociedad aymara de características culturales tradicionales.

Conviene recordar que textos, programas y profesores conforman una unidad cultural $y$, por tanto, representan los mismos modelos, valores e ideologías de la sociedad regional dominante. Profesores y textos detentan los mismos modelos de ser hombre y ser mujer. ¿Cuáles son los contenidos valóricos y cuáles son los modelos de género que ha transmitido? ¿Cómo éstos han influido en los cambios que han experimentado los roles de género?

La escuela, a través de los textos de apresto y libros de lectura, transmite los estereotipos de género que nuestra propia cultura mestiza ha construido, los cuales reducen al hombre y a la mujer a la ecuación mujermadre-dueña de casa / hombre-proveedor. El mensaje unificado de maestros, programas y textos expone una división del trabajo por género de tipo excluyente. Los estereotipos reducen a mujeres y a hombres a espacios rígidos y definidos: las primeras adscritas al hogar, al espacio doméstico y privado y los segundos al espacio público y diversificado socialmente. Esta forma de pensar los roles de género conduce a la dependencia económica de las mujeres, de quienes se dice que no trabajan, por lo que la unidad familiar es mantenida por un hombre, el cual cumple el rol de único sostenedor económico del hogar y valorado también en la medida que cumpla con este mandato social.

De esta manera, reforzados una y otra vez a través del discurso del profesor y los textos, no es difícil aventurar que los niños y niñas aymara así socializados se hayan apropiado de estos ideales y hayan así formado un proyecto de vida acorde. No obstante, éste es posible lograrlo en el ámbito urbano, mas no en el campesino. En este contexto la tendencia a emigrar e instalarse en las ciudades constituye una de las principales aspiraciones. Para ello, contribuyen los valores estéticos propuestos en las imágenes de los textos analizados. A través de las figuras femeninas y masculinas, se transfieren a niños y niñas aymaras modelos de mujeres y hombres ajenos a su cultura, cuyas cualidades han ido adquiriendo mayor valoración sobre todo en las generaciones más jóvenes. Junto con esto, son transmitidos, a su vez, otros valores como la anteposición de la realización personal por sobre los intereses de la familia como unidad.

Permitámonos ahora, deliberar en torno a la segunda pregunta planteada: ¿Cómo estos contenidos han influido en los cambios que han experimentado los roles de género?

Lo expuesto aquí es congruente con lo manifestado por mujeres y hombres aymaras en cuanto a su experiencia como alumnos/as y el futuro que desean para sus hijos/ as. Ellos/as mismos/as dan cuenta de la preferencia familiar por la educación de los varones, como del mayor apoyo que se les da en la culminación de estudios superiores, lo que claramente coincide con el modelo transferido a través de la escuela y con el rol familiar que se interpreta a través de él. Sabemos que este fenómeno, vinculado asimismo a la movilidad de los jóvenes (mayormente varones), especialmente hacia centros urbanos, ha significado una recarga de trabajo en las mujeres de la familia, quienes han asumido las tareas que antiguamente desarrollaban los niños/as en la casa, sin la contraparte masculina que tiende a desentenderse de las actividades domésticas, algunas antiguamente realizadas indistintamente por hombres y mujeres. Así es como la movilidad poblacional los ha afectado más a ellos, al asumir que son los que deben sostener económicamente el hogar, razón por la cual deben emigrar con el objeto de conseguir empleos asalariados. En este sentido, el rol que antiguamente cumplían en la reproducción del hogar ha ido variando con el tiempo. Mujeres y hombres aymaras han reorientado sus roles adecuándolos a los modelos de la cultura dominante.

El sistema a su vez opera de tal manera que se crean nuevas necesidades, dentro de las cuales asistir a la escuela sería una de las fundamentales, puesto que al 
incorporar los ideales y proyectos de la cultura dominante el individuo precisa de las herramientas que la misma cultura dominante ofrece para lograrlos. Es así que hoy mujeres y hombres aymaras consideran fundamental que sus hijos e hijas ingresen al sistema escolar, continúen estudios secundarios e incluso ingresen a la universidad.

Si bien el trabajo campesino es desvalorado por mujeres y hombres aymaras, son estos últimos quienes han tratado de salir conscientemente de esta condición. Ellos aspiran a vivir en la ciudad y desarrollarse en ella, pero paradójicamente sin desvincularse del todo de sus lugares de origen.

Agradecimientos El presente artículo se inserta dentro de los proyectos de Investigación FONDECYT Regular 1110980 (aún en ejecución) e Investigación Mayor en Ciencia y Tecnología de la Universidad de Tarapacá 374011. Asimismo, parte de la información primaria fue obtenida con anterioridad, durante el desarrollo del proyecto FONDECYT de Género 1020507.

\section{$*$ Referencias citadas}

CARRASCO, A. M., 1998. Constitución de género y ciclo vital entre los aymaras contemporáneos del norte de Chile. Chungara 30 (1): 87-103.

COX, C., 1997. La Reforma de la educación chilena: Contexto, Contenidos, Implementación. Programa de la Reforma Educativa en América Latina, PREAL, Santiago, Chile.

DUFFLOCQ, A., 1964. Silabario Hispano Americano, Edición 76. Editorial Lord Cochrane, Santiago, Chile.

DÍAZ, S., F. FERNÁNDEZ y L. MILANÉS, 1985. Marka Masi, Somos del mismo pueblo. Universidad de Tarapacá, Arica, Chile.

DÍAZ, A. y R. RUZ, 2009. Estado, escuela chilena y población andina en la ex Subdelegación de Putre. Acciones y reacciones durante el período de post Guerra del Pacífico (1883-1929), Polis $8(24): 311-340$.

ECHEVERRÍA, C., 1999. Estado y educación rural en el norte de Chile. Serie Documentos de Trabajo. Taller de Estudios Andinos, Arica, Chile.

GAVILÁN, V. 1995. Una aproximación a las relaciones de género entre lo aymara del norte de Chile, Temas Regionales 3: 42-59.

GAVILÁN, V., y H. GONZÁLEZ, 2002. Hacia una teoría aymara de la división del trabajo por género en las comunidades del altiplano del norte de Chile. Chungara 34 (1): 101-117.

GONZÁLEZ, H., y H. GUNDERMANN, 1995. Contribución a la historia de la propiedad aymara. Editado por CONADI. Agencia de Cooperación Internacional y Agencia Española de Cooperación Internacional, Santiago, Chile.
GONZÁLEZ, S., 2002. Chilenizando a Tunupa. La escuela pública en el Tarapacá andino, 1880-1990. DIBAM-UNAP, Santiago, Chile.

GUNDERMANN, H., 1985. La visión aymara de la escuela, los profesores y la educación. Instituto de Antropología Universidad de Tarapacá y Fundación Interamericana, Arica, Chile.

1986. Un ensayo de crítica a los programas educacionales aplicados a los aimara. Revista de Tecnología Educativa IX (3): 161-181.

GUNDERMANN, H., J. VERGARA y A. DÍAZ, 2011. Historia moderna de una lengua originaria: el jaqi aru en Chile. En RLA, Revista de Lingǘstica Teórica y Aplicada 49 (1): 69-108.

GUZMÁN, M., 1928. El lector chileno. Libro Primero, Talleres "La Nación", Santiago de Chile.

LABARCA, A., 1928. Nuevo lector americano. Editorial Zig-Zag, Santiago, Chile.

MAMANI, M., 1985. Bilingüismo y su problemática educacional en la provincia de Parinacota, Arica: Universidad de Tarapacá. Universidad de Tarapacá, Arica, Chile.

MATTE, C., 1967. Nuevo Método. Edición 65 de la Sociedad de Instrucción Primaria. Editorial Zig-Zag, Santiago de Chile.

PODESTÁ, J., 1981. Influencias de la educación fiscal en las comunidades aymaras del Norte Grande chileno. Memoria de Licenciatura. Universidad del Norte, Antofagasta, Chile.

POWER, A., 1947. Mi Tierra, Silabario para adultos. Editorial ZigZag. Santiago, Chile. 
RIQUELME, B., L. GÓMEZ y D. VALENZUELA, 1988. Lea en colores (12 ${ }^{\text {a }}$ edición). Editorial Zig-Zag, Santiago, Chile.

TUDELA, P., 1993-1994. Chilenización y cambio ideológico entre los aymaras de Arica (1883-1930). Intervención religiosa y secularización. Revista de Antropología 12: 201-231.
VAN KESSEL, J., 1992. Holocausto al progreso: Los aymaras de Tarapacá. Editorial Hisbol, La Paz, Bolivia.

WAINERMAN, C. y B. DE RAIJMAN, 1987. Sexismo en los libros de lectura de la escuela primaria. Ediciones de Ides, Buenos Aires, Argentina. 